\title{
Investigation of The Dielectric Properties Of (Cu, Tl) 1234 Added with Graphene
}

\author{
Ibrahim.Younes ${ }^{1}$, Hadi.Basma ${ }^{1}$, Mohamad.Anas ${ }^{2} \&$ Ramadan.Awad $^{1}$ \\ ${ }^{1}$ Beirut Arab University, Material Science lab, Debbieh, Lebanon \\ ${ }^{2}$ Alexandria University, Superconductivity and Metallic-Glass Lab, Alexandria, Egypt \\ Correspondence: Hadi Basma, Beirut Arab University, Material Science lab, Debbieh, Lebanon. Tel: 96-1343- \\ 9327. E-mail: hadibassma@gmail.com
}

Received: January 1, 2019

doi:10.5539/mas.v13n4p12
Accepted: February 23, 2019

Online Published: March 13, 2019

URL: https://doi.org/10.5539/mas.v13n4p12

\begin{abstract}
Superconducting samples of type $\left(\mathrm{Cu}_{0.5} \mathrm{Tl}_{0.5}\right)-1234$ were prepared at normal pressure via one step of conventional solid state reaction technique, and added with $\mathrm{x}$ wt.\% of graphene $(0 \leq \mathrm{x} \leq 0.1)$. X-ray powder diffraction (XRD) shows that the addition of graphene does not alter the tetragonal structure and the lattice parameters of the samples. Fourier Transform Infrared (FTIR) measurements indicate the non-uniform distribution of graphene inside the $\left(\mathrm{Cu}_{0.5} \mathrm{Tl}_{0.5}\right)$-1234 phase. While the Scanning Electron Microscope (SEM) images reveal the increase of the intergrain connectivity. The superconducting transition temperature $T_{c}$, obtained from Ac magnetic susceptibility measurements, shows an enhancement up to $\mathrm{x}=0.04 \mathrm{Wt}$. $\%$, followed by a deterioration for $\mathrm{x}>0.04$. The frequency dependence of the dielectric properties of the samples was experimentally investigated at different temperatures $(110 \mathrm{~K} \leq \mathrm{T} \leq 260 \mathrm{~K})$. The real and imaginary parts $\left(\varepsilon^{\prime}\right.$ and $\left.\varepsilon^{\prime \prime}\right)$ of dielectric constant increase up to $\mathrm{x}=0.1$. The study of $\varepsilon^{\prime}$ and $\varepsilon^{\prime \prime}$, the dielectric loss $(\tan \delta)$ and the ac-conductivity $\left(\sigma_{a c}\right)$ have shown that the variation of frequency, temperature and addition of graphene allows the tuning of these parameters for various applications.
\end{abstract}

Keywords: $\left(\mathrm{Cu}_{0.5} \mathrm{Tl}_{0.5}\right)-1234$, graphene, FTIR, Dielectric measurements

\section{Introduction}

The high temperature superconductor $\left(\mathrm{Cu}_{0.5} \mathrm{Tl}_{0.5}\right) \mathrm{Ba}_{2} \mathrm{Ca}_{3} \mathrm{Cu}_{4} \mathrm{O}_{12-\delta}(\mathrm{Cu}, \mathrm{Tl}) 1234$ is a promising candidate for various practical applications including superconducting electromagnets used in fusion reactors and focusing magnets used in particle accelerators [1]. It has a high $T_{c}$, can be prepared under normal pressure, a low superconducting anisotropy $(\gamma=1.6)$, a long coherence length along c-axis $\left(\xi_{\mathrm{c}}=1 \mathrm{~nm}\right)$ and a small penetration depth $\left(\lambda_{\mathrm{c}}=220 \mathrm{~nm}\right)$ with a high $\mathrm{J}_{\mathrm{c}}[2]$. The effect of nanosized additions on $(\mathrm{Cu}, \mathrm{Tl}) 1234$ has been investigated by many researchers [3-5] and all results have shown that the addition of nanoparticles in a suitable amount improves the structure and superconducting parameters. Awad investigated the effect of $\mathrm{MgO}$ nanoparticles on $\left(\mathrm{Cu}_{0.25} \mathrm{Tl}_{0.75}\right)-1234$ superconducting phase [6]. Both electrical and mechanical properties including critical current density, superconducting transition temperature and Vickers microhardness were enhanced up to $\mathrm{x}=0.06 \mathrm{wt} . \%$. The effect of the addition of graphene to HTSCS is still a novel research topic. Sudesh et al.,[7] explored the effect of addition of graphene on superconducting properties of $\mathrm{MgB}_{2}$. The critical current density, upper critical field and irreversibility field were all enhanced with graphene addition. Wei et al. [8] studied the effect of graphene addition on ac Susceptibility and Superconducting Properties of $\mathrm{YBa}_{2} \mathrm{Cu}_{3} \mathrm{O}_{-\delta}$. A noticeable enhancement in $\mathrm{J}_{\mathrm{c}}$ and grains coupling with the addition of graphene was observed. The effect of graphene addition on $\left(\mathrm{Tl}_{0.85} \mathrm{Cr}_{0.15}\right) \mathrm{Sr}_{2} \mathrm{CaCu}_{2} \mathrm{O}_{7}$. $\delta$ superconductor was also examined [9].The superconducting transition temperature decreased with the increase in amount of added graphene, while the critical current density was enhanced for low addition and deteriorated for higher additions of graphene. The investigation of the dielectric properties of high temperature superconductors can provide important parameters for the design of many electronics applications. In general, materials of high dielectric constant are of important applications in memory devices and supercapacitors [10].

Furthermore, the dielectric constants present an evidence about the binding forces that links the mobile carriers between the conducting planes, their interfaces and the charge reservoir layer in high superconducting transition temperature cuprates. Inspite of being extensively characterized, there is a still a lack of information concerning the dielectric properties of cuprates. Several factors affect the conduction mechanisms of electronic devices. These factors depend on temperature, frequency, surface charges, manufacture process, space charge effects caused by 
oxygen ions, and doping contents. Hence, the dielectric properties do not maintain the same values at different frequencies and temperatures. As a result, the investigation of the dielectric properties and ac conductivity for different ranges of frequency and temperature is significant. Mumtaz et al. [11] studied the dielectric properties of $\mathrm{Cu}_{0.5} \mathrm{Tl}_{0.5} \mathrm{Ba}_{2}\left(\mathrm{Ca}_{2-\mathrm{y}} \mathrm{Mg}_{y}\right)\left(\mathrm{Cu}_{0.5} \mathrm{Zn}_{2.5}\right) \mathrm{O}_{10-\delta}$ and $\mathrm{Cu}_{0.5} \mathrm{Tl}_{0.5} \mathrm{Ba}_{2} \mathrm{Ca}_{3} \mathrm{Cu}_{4} \mathrm{O}_{12-\delta}$ superconductors . The dielectric constants were found to be intensely influenced by the applied ac-field frequency. Furthermore, Awad [12] found that normal dielectric constant for $\mathrm{Cu}_{0.5} \mathrm{Tl}_{0.5} \mathrm{Ba}_{2} \mathrm{Ca}_{2-x} \mathrm{Cd}_{x} \mathrm{Cu}_{3} \mathrm{O}_{10-\delta}$ was strongly dependent on $\mathrm{Cd}$ content and correlated with the normal electrical resistivity results. Younes et al.[13] investigated the dielectric properties of $\mathrm{Cu}_{0.5} \mathrm{Tl}_{0.5} \mathrm{Ba}_{2} \mathrm{Ca}_{3} \mathrm{Cu}_{4-\mathrm{y}} \mathrm{Zn}_{\mathrm{y}} \mathrm{O}_{12-\delta}(\mathrm{y}=0,3)$. The $\mathrm{Zn}$-doped samples showed a decrease in the dielectric loss factor. This loss was attributed to the polarization arising from separation of charges between the $\mathrm{Cu}_{0.5} \mathrm{Tl}_{0.5} \mathrm{Ba}_{2} \mathrm{O}_{4-\delta}$ charge reservoir layer and mobile carriers in the conducting $\mathrm{CuO}_{2} / \mathrm{ZnO}_{2}$ planes. Furthermore, Mohammed N.H [14] explored the effect of nano sized $\mathrm{MgO}$ addition on $\mathrm{Cu}_{0.25} \mathrm{Tl}_{0.75} \mathrm{Ba}_{2} \mathrm{Ca}_{3} \mathrm{Cu}_{4} \mathrm{O}_{12-\delta}$ superconducting Phase. $\varepsilon^{\prime}$ was found to be frequency and temperature dependent for all amounts of $\mathrm{MgO}$ addition. $\varepsilon^{\prime \prime}$ and $\tan \delta$ showed a dispersion toward lower frequencies with the decrease of operating temperature. Mumtaz et al. [15] explored the effects of $\mathrm{NiFe}_{2} \mathrm{O}_{4}$ nanoparticles on dielectric properties of $\mathrm{Cu}_{0.5} \mathrm{Tl}_{0.5} \mathrm{Ba}_{2} \mathrm{Ca}_{2} \mathrm{Cu}_{3} \mathrm{O}_{10-\delta}$ superconducting phase. The dielectric properties were highly influenced by the temperature and the amount of added $\mathrm{NiFe}_{2} \mathrm{O}_{4}$. Khan et al [16] investigated Dielectric response of $\mathrm{Cu}_{0.5} \mathrm{Tl}_{0.5} \mathrm{Ba}_{2} \mathrm{Ca}_{2} \mathrm{Cu}_{3-\mathrm{x}} \mathrm{M}_{\mathrm{x}} \mathrm{O}_{10-\delta}(\mathrm{M}=\mathrm{Cd}, \mathrm{Zn}, \mathrm{Ni}$; $\mathrm{x}=0$, 1.5) Superconductors in the low frequency region. Samples doped with $\mathrm{Cd}$ have shown a maximum suppression. This report studies the effect of graphene addition on the structure, ac magnetic susceptibility as well as the dielectric properties of $(\mathrm{Cu}, \mathrm{Tl}) 1234$ superconducting phase. The frequency dependence of the dielectric constants $\varepsilon^{\prime}, \varepsilon^{\prime \prime}, \tan \delta$ and $\sigma_{\text {ac }}$ were measured at a temperature range $110 \mathrm{~K} \leq \mathrm{T} \leq 260 \mathrm{~K}$.

\section{Methods}

\subsection{Sample Preparation}

Superconducting samples $(\mathrm{CH})_{\mathrm{nx}} /\left(\mathrm{Cu}_{0.5} \mathrm{Tl}_{0.5}\right) \mathrm{Ba}_{2} \mathrm{Ca}_{3} \mathrm{Cu}_{4} \mathrm{O}_{12-\delta}$, with different addition levels $0.0 \leq \mathrm{x} \leq 0.1 \mathrm{wt} \%$ were prepared by the conventional one-step solid-state reaction technique. The oxides $\mathrm{Tl}_{2} \mathrm{O}_{3}, \mathrm{BaO}_{2}, \mathrm{CaO}$, $\mathrm{CuO}$, and $(\mathrm{CH})_{n}$ powders, with high purity $\geq 99.9 \%$, were weighted in appropriate ratios. They were mixed and well crushed using agate mortar, then sifted using $60 \mu \mathrm{m}$ sieve to improve the homogeneity of the mixture. The sifted powder was pressed in a disc of dimensions (diameter $1.6 \mathrm{~cm}$ and thickness $1.5 \mathrm{~mm}$ ). The pellets were wrapped carefully in silver foils and placed in sealed quartz tubes to reduce thallium evaporation during the heating process. Furthermore, the tubes were fired in the box furnace at two different rates $\left(4^{\circ} \mathrm{C} / \mathrm{min}\right.$ to $710^{\circ} \mathrm{C}, 2^{\circ} \mathrm{C} / \mathrm{min}$ from $710{ }^{\circ} \mathrm{C}$ to $850{ }^{\circ} \mathrm{C}$ ) then, held at this temperature for 4 hours after which they were cooled down to room temperature at a rate $6{ }^{\circ} \mathrm{C} / \mathrm{min}[14]$.

\subsection{Characterization-Dielectric Measurements}

The prepared samples were characterized by X-ray powder diffraction (XRD) using the Bruker D8 advance powder diffractometer with $\mathrm{Cu}-\mathrm{K}_{\alpha}$ radiation $(\lambda=1.54056 \AA)$ in the range $5^{\circ} \leq 2 \theta \leq 70^{\circ}$. The JEOL JSM-5300 scanning electron microscope was used to examine the microstructure morphology of the samples. Fourier transform infrared spectroscopy analysis was done by FTIR 8400S Shimadzu between 400-700 $\mathrm{cm}^{-1}$ wavenumber ranges. The ac magnetic susceptibilities were measured using a quantum design PPMS system equipped with a 9-Tesla superconducting magnet at a temperature range from 25 to $135 \mathrm{~K}$ all runs at a fixed frequency of $1 \mathrm{KHz}$. The dielectric properties of the prepared samples were measured at different ranges of frequency and temperature using HIOKI 3532- 50 LCR Hi-tester. The low temperature dielectric measurements were done using liquid nitrogen. By measuring the capacitance and dielectric loss tangent $(\tan \delta)$ and the dimension of the sample; the dielectric constants $\left(\varepsilon^{\prime}\right.$ and $\left.\varepsilon^{\prime \prime}\right)$ and ac conductivity $\left(\sigma_{\mathrm{ac}}\right)$ were determined using the following expressions [15]

$$
\begin{aligned}
\varepsilon^{\prime} & =\frac{C d}{\varepsilon_{0} A}, \\
\varepsilon^{\prime \prime} & =\varepsilon^{\prime} \cdot \tan \delta, \\
\sigma_{a c} & =\varepsilon^{\prime} . \varepsilon_{0} \omega \tan \delta .
\end{aligned}
$$

Where $\varepsilon_{0}$ is permittivity of free space, $A$ is the area of electrode, $d$ is the sample thickness, $\omega=2 \pi f$ is the angular frequency of applied field.

\section{Results}

Figure 1 shows the XRD pattern of $\left((\mathrm{CH})_{\mathrm{n}}\right)_{\mathrm{x}} /\left(\mathrm{Cu}_{0.5} \mathrm{Tl}_{0.5}\right) \mathrm{Ba}_{2} \mathrm{Ca}_{3} \mathrm{Cu}_{4} \mathrm{O}_{12-\delta}$, with $0.0 \leq \mathrm{x} \leq 0.1$ wt. \%. Most of the diffraction peaks belong to tetragonal structure of $(\mathrm{Cu}, \mathrm{Tl})-1234$ phase with a space group $\mathrm{P} 4 / \mathrm{mmm}$. The most intense peak appeared at $2 \theta=31.92^{\circ}$ for pure sample $(\mathrm{x}=0.00 \mathrm{wt} . \%)$ and altered in some samples to $2 \theta=33.2^{\circ}$. 
The Lattice parameters a and $\mathrm{c}$ for tetragonal structure are calculated and listed in Table 1. The relative volume fractions of $(\mathrm{Cu}, \mathrm{Tl})-1234, \mathrm{BaCuO}_{2}$ and $\left(\mathrm{Cu}_{0.5} \mathrm{Tl}_{0.5}\right)-1223$ phases are determined by comparing all the peak intensities [17], and are listed in Table 1. The relative volume fraction of $(\mathrm{Cu}, \mathrm{Tl})-1234$ increases up to $\mathrm{x}=0.04$ wt. $\%$, then it decreases with further increases in $\mathrm{x}$.

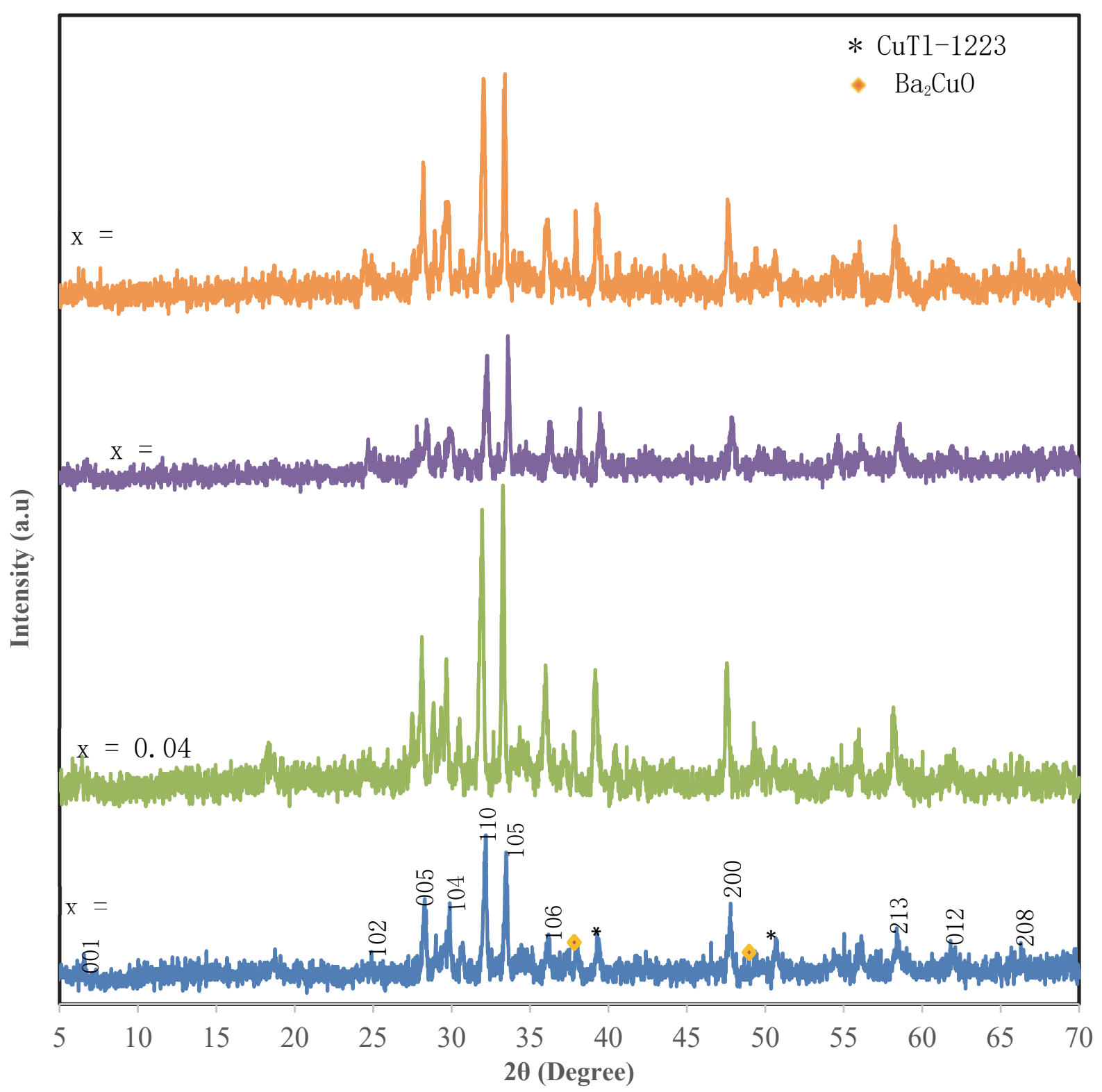

Figure 1. XRD patterns for $\left((\mathrm{CH})_{\mathrm{n}}\right)_{\mathrm{x}} /\left(\mathrm{Cu}_{0.5} \mathrm{Tl}_{0.5}\right) \mathrm{Ba}_{2} \mathrm{Ca}_{3} \mathrm{Cu}_{4} \mathrm{O}_{12-\delta}$ with $0.00 \leq \mathrm{x} \leq 0.10$ wt. $\%$

Table 1. Variation of the, volume fraction, $\mathrm{T}_{\mathrm{c}}$, average grain size, lattice parameters, and frequency exponent (s) for $\left((\mathrm{CH})_{\mathrm{n}}\right)_{\mathrm{x}} /\left(\mathrm{Cu}_{0.5} \mathrm{Tl}_{0.5}\right) \mathrm{Ba}_{2} \mathrm{Ca}_{3} \mathrm{Cu}_{4} \mathrm{O}_{12-\delta}$ with $0.00 \leq \mathrm{x} \leq 0.10$ wt. \%.

\begin{tabular}{|c|c|c|c|c|c|c|c|c|}
\hline \multirow[t]{2}{*}{$\mathrm{x}$} & \multicolumn{3}{|c|}{ Volume fraction $(\%)$} & \multirow[t]{2}{*}{$\mathrm{T}_{\mathrm{C}}(\mathrm{K})$} & \multirow{2}{*}{$\begin{array}{c}\text { Average } \\
\text { grain } \\
\text { size } \\
(\mu \mathrm{m})\end{array}$} & \multirow[t]{2}{*}{$\mathrm{a}(\AA)$} & \multirow[t]{2}{*}{$\mathrm{c}(\boldsymbol{\AA})$} & \multirow[t]{2}{*}{$\mathbf{s}$} \\
\hline & $(\mathrm{Cu}, \mathrm{Tl}) 1234$ & $(\mathrm{Cu}, \mathrm{Tl}) 1223$ & $\mathrm{BaCuO}_{2}$ & & & & & \\
\hline 0.00 & 90.66 & 8.63 & 0.71 & 108 & 1.9 & 3.868 & 18.916 & 1.640 \\
\hline 0.02 & 90.68 & 8.26 & 1.06 & 113 & 2.2 & 3.849 & 18.948 & 1.537 \\
\hline
\end{tabular}




\begin{tabular}{lllllllll}
\hline 0.04 & 96.29 & 2.48 & 1.23 & 116 & 2.0 & 3.848 & 18.964 & 1.634 \\
0.06 & 93.32 & 4.18 & 2.51 & 110 & 1.4 & 3.850 & 18.965 & 1.744 \\
0.08 & 89.07 & 7.28 & 3.65 & 104 & 1.8 & 3.845 & 18.942 & 1.469 \\
0.10 & 84.91 & 10.63 & 4.46 & 95 & 1.6 & 3.855 & 18.9242 & 1.714 \\
& & & & & & & &
\end{tabular}

Figures 2(a),(b) (c) and (d) represent the SEM images of graphene added to $\left(\mathrm{Cu}_{0.5} \mathrm{Tl}_{0.5}\right)-1234$ superconductor phase with $\mathrm{x}=0.00,0.04,0.08$ and $0.10 \mathrm{wt} . \%$, respectively. Fig 2(a) shows small rectangular-shape plates corresponding to the formation of $(\mathrm{Cu}, \mathrm{Tl})-1234$ phase. The formation of rectangular grains was improved with graphene addition for $\mathrm{x}-0.04 \mathrm{wt} . \%$. For higher additions of graphene the rectangular shapes disappear and the formation of spherical non uniform shapes is observable. The values of the average grain size are listed in table 1.

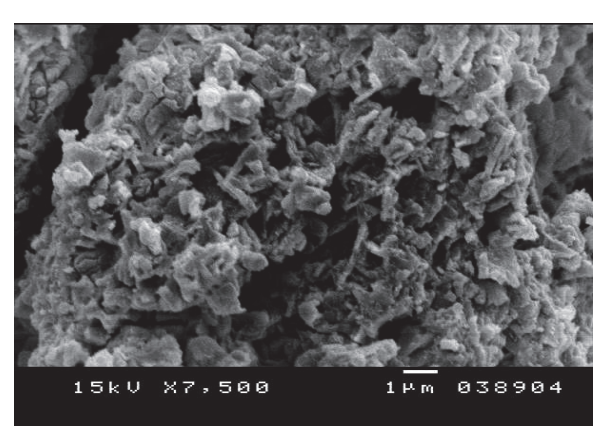

(a)

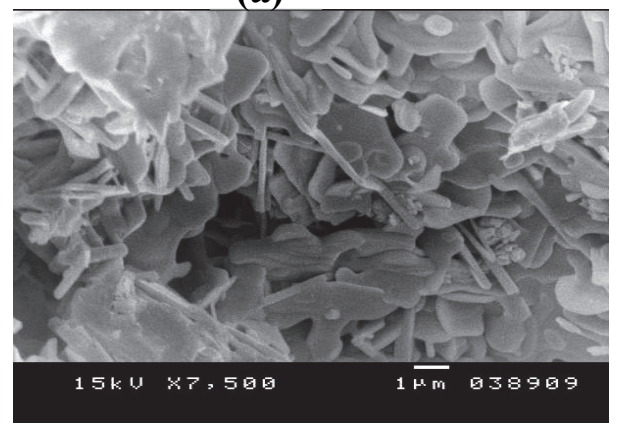

(c)

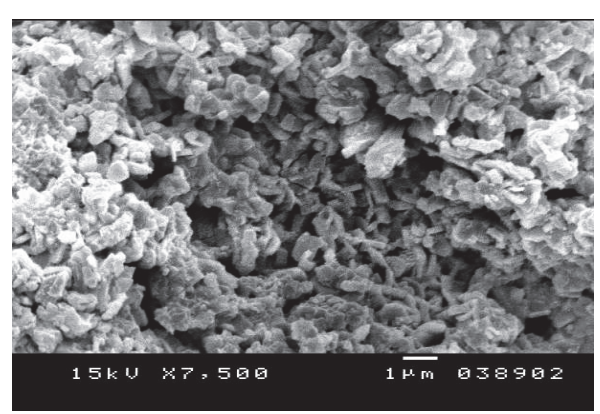

(b)

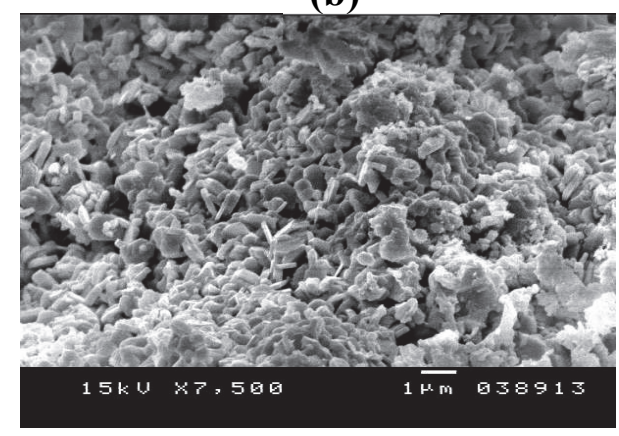

(d)

Figure 2. (a),(b),(c) and (d) the scanning electron microscope (SEM) images of $\left((\mathrm{CH})_{\mathrm{n}}\right)_{\mathrm{x}} /\left(\mathrm{Cu}_{0.5} \mathrm{Tl}_{0.5}\right) \mathrm{Ba}_{2} \mathrm{Ca}_{3} \mathrm{Cu}_{4} \mathrm{O}_{12-\delta}$ with $\mathrm{x}=0.00,0.04,0.08$ and 0.10 wt. $\%$

Figure 3 shows the real part of the ac magnetic susceptibility $\chi$ 'versus temperature for $\left((\mathrm{CH})_{\mathrm{n}}\right)_{\mathrm{x}} /\left(\mathrm{Cu}_{0.5} \mathrm{Tl}_{0.5}\right) \mathrm{Ba}_{2} \mathrm{Ca}_{3} \mathrm{Cu}_{4} \mathrm{O}_{12-\delta}$ with different additions of graphene at $H=3$ Oe .The superconducting transition temperature $T_{\mathrm{c}}$ is the temperature at which $\chi^{\prime}$ changes its sign from a positive to a negative sign. . The values of $T_{\mathrm{c}}$ are listed in table 1 and are plotted in the inset of figure 3 . 


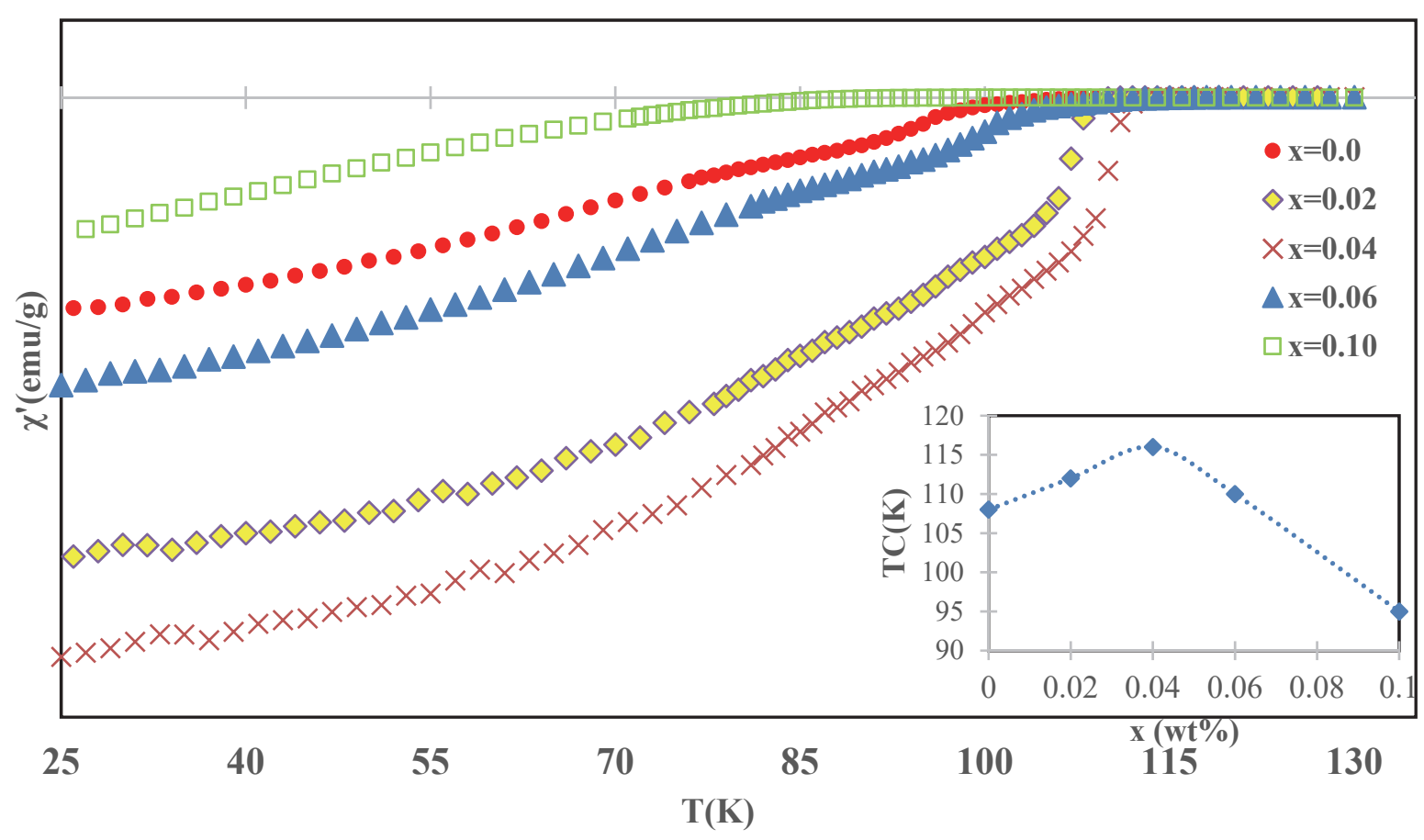

Figure 3. $\chi^{\prime}$ versus temperature curves for $\left((\mathrm{CH})_{\mathrm{n}}\right)_{\mathrm{x}} /\left(\mathrm{Cu}_{0.5} \mathrm{Tl}_{0.5}\right) \mathrm{Ba}_{2} \mathrm{Ca}_{3} \mathrm{Cu}_{4} \mathrm{O}_{12-\delta}$ with $0.00 \leq \mathrm{x} \leq 0.10$ wt. \%. The inset shows the variation of $\mathrm{T}_{\mathrm{c}}$ with $\mathrm{x}$

The FTIR absorption spectra of $\left((\mathrm{CH})_{\mathrm{n}}\right)_{\mathrm{x}} /\left(\mathrm{Cu}_{0.5} \mathrm{Tl}_{0.5}\right) \mathrm{Ba}_{2} \mathrm{Ca}_{3} \mathrm{Cu}_{4} \mathrm{O}_{12-\delta}(0.0 \leq \mathrm{x} \leq 0.1$ wt. \%) in the range from 400 to $700 \mathrm{~cm}^{-1}$ are shown in figure 4 . The bands in the range $400-540 \mathrm{~cm}^{-1}, 541-600 \mathrm{~cm}^{-1}$ and $670-700 \mathrm{~cm}^{-1}$ correspond to the apical oxygen atoms, $\mathrm{CuO}_{2}$ planner oxygen atoms and $\mathrm{O}_{\delta}$ atoms in the charge reservoir layer, respectively.

Figure 5 shows the frequency dependence of $\varepsilon^{\prime}$ at different temperatures for $\left(\mathrm{Cu}_{0.5} \mathrm{Tl}_{0.5}\right) \mathrm{Ba}_{2} \mathrm{Ca}_{3} \mathrm{Cu}_{4} \mathrm{O}_{12-\delta}$. The general behavior of $\varepsilon^{\prime}$ displays a fast decrease with frequency for all temperatures. The variation of $\varepsilon^{\prime}$ with frequency for $\left((\mathrm{CH})_{\mathrm{n}}\right)_{\mathrm{x}} /\left(\mathrm{Cu}_{0.5} \mathrm{Tl}_{0.5}\right) \mathrm{Ba}_{2} \mathrm{Ca}_{3} \mathrm{Cu}_{4} \mathrm{O}_{12-\delta}(0.00 \mathrm{wt} . \% \leq \mathrm{x} \leq 0.10 \mathrm{wt} . \%)$ at $\mathrm{T}=110 \mathrm{~K}$ is shown in the inset of Figure 5. $\varepsilon^{\prime}$ shows an increase with $\mathrm{x}$, mostly significant for the sample with $\mathrm{x}=0.1 \mathrm{wt} \%$ at which it recorded its highest value $\left(9.5 \times 10^{6}\right)$

The complex dielectric constant $\left(\varepsilon^{*}=\varepsilon^{\prime}+\mathrm{j} \varepsilon^{\prime \prime}\right)$ originates from four different polarizations which are strongly dependent on the frequency range. In the low frequency range $\left(10^{3} \mathrm{~Hz}\right)$, the space charge or interfacial polarization arises. In the frequency range $10^{3}$ to $10^{6} \mathrm{~Hz}$ the dipolar polarization occurs. The atomic and ionic polarizations take place at frequencies ranging from $10^{10}$ to $10^{13} \mathrm{~Hz}$. At high frequency of $10^{15} \mathrm{~Hz}$, the electronic polarization is observed [18]. The dipolar and space charge polarization play the main role in our measurements.

The imaginary part of the dielectric constant $\varepsilon$ ", reflects the amount of energy the attenuated of energy at defect sites, grain boundaries and localized charge densities when the samples are exposed to an external electric field. The frequency dependence of $\varepsilon^{\prime}$ at different temperatures for $\left(\mathrm{Cu}_{0.5} \mathrm{Tl}_{0.5}\right) \mathrm{Ba}_{2} \mathrm{Ca}_{3} \mathrm{Cu}_{4} \mathrm{O}_{12-\delta}$ is shown in figure 6 . The $(\mathrm{Cu}-\mathrm{Tl}) 1234$ phase exhibit the dielectric dispersion, in low frequency range, where $\varepsilon$ " decreases as the frequency increases with no observable effect of temperature. It is shown in the inset of Figure.6, that $\varepsilon$ " shows a similar behavior for all values of $\mathrm{x}$ at $\mathrm{T}=110 \mathrm{~K}$. 


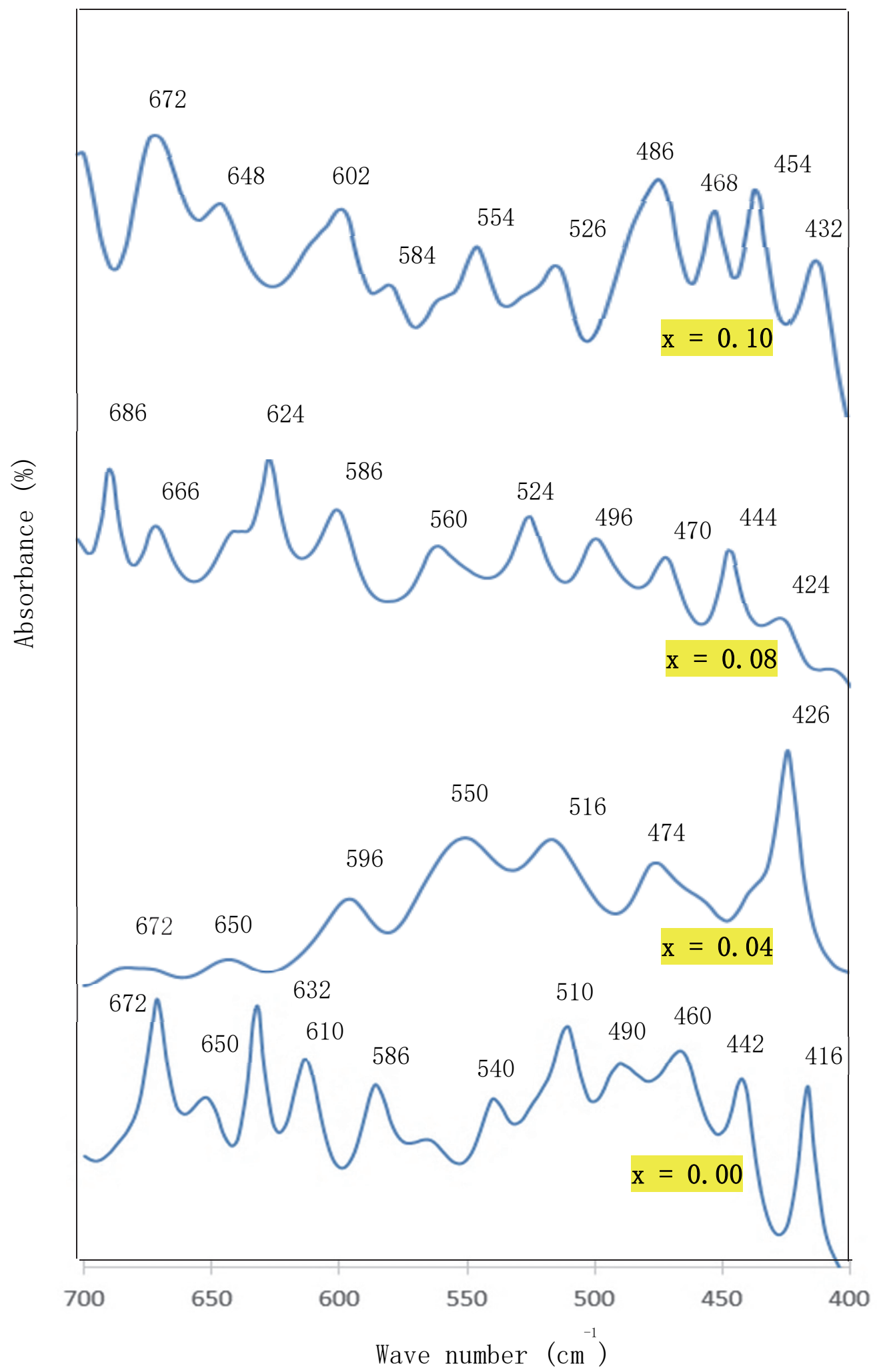

Figure 4. The FTIR absorption spectra of $\left((\mathrm{CH})_{\mathrm{n}}\right)_{\mathrm{x}} /\left(\mathrm{Cu}_{0.5} \mathrm{Tl}_{0.5}\right) \mathrm{Ba}_{2} \mathrm{Ca}_{3} \mathrm{Cu}_{4} \mathrm{O}_{12-\delta}$ with $0.00 \leq \mathrm{x} \leq 0.10$ wt. \% 


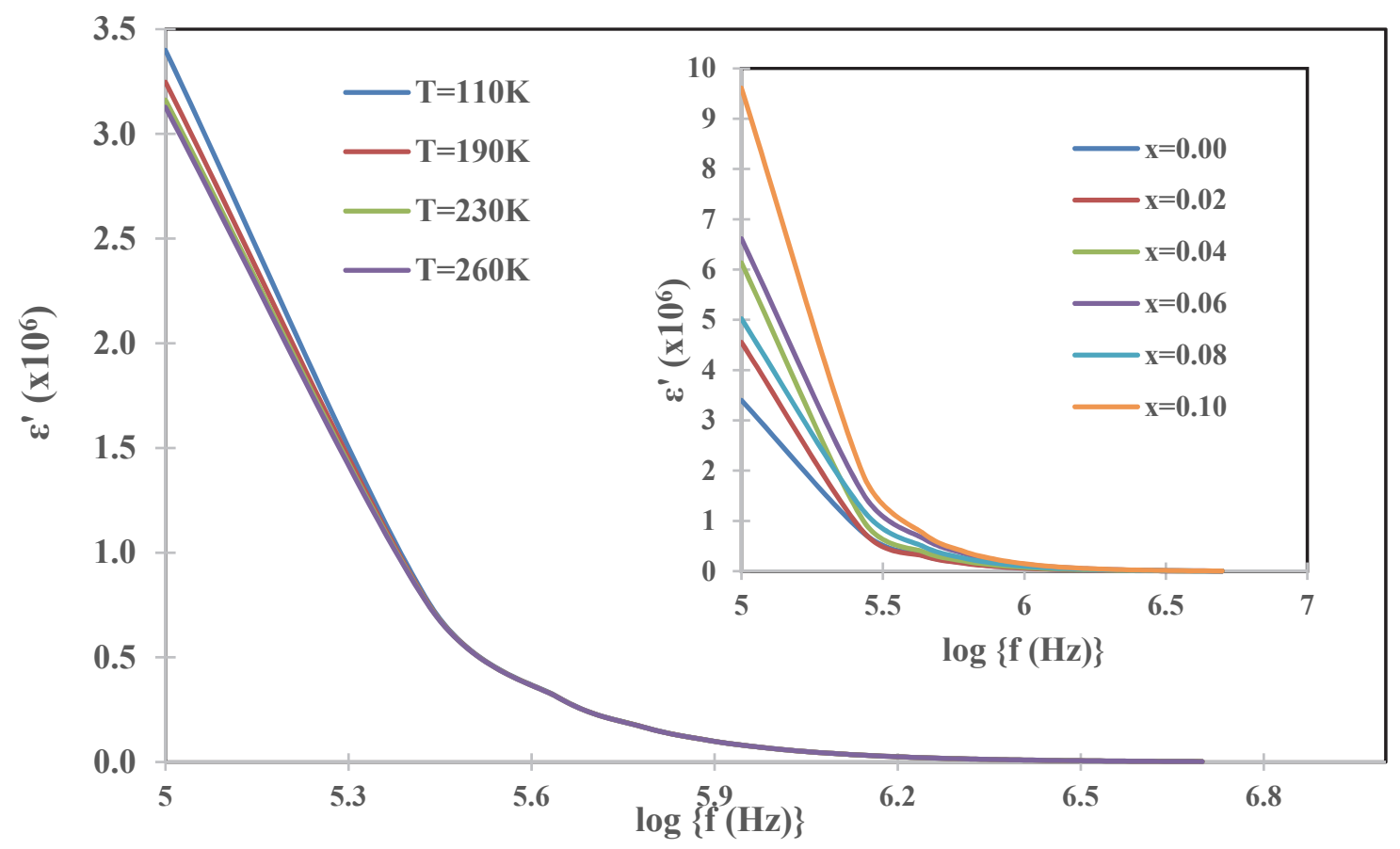

Figure 5. Frequency dependence of $\varepsilon^{\prime}$ at different temperatures for $\left(\mathrm{Cu}_{0.5} \mathrm{Tl}_{0.5}\right) \mathrm{Ba}_{2} \mathrm{Ca}_{3} \mathrm{Cu}_{4} \mathrm{O}_{12-\delta}$. The inset represents the Frequency dependence of' $\varepsilon$ ' at $\mathrm{T}=110 \mathrm{~K}$ for $\left((\mathrm{CH})_{\mathrm{n}}\right)_{\mathrm{x}} /\left(\mathrm{Cu}_{0.5} \mathrm{Tl}_{0.5}\right) \mathrm{Ba}_{2} \mathrm{Ca}_{3} \mathrm{Cu}_{4} \mathrm{O}_{12-\delta}$ with $0.00 \leq \mathrm{x} \leq$ 0.10 wt. $\%$.

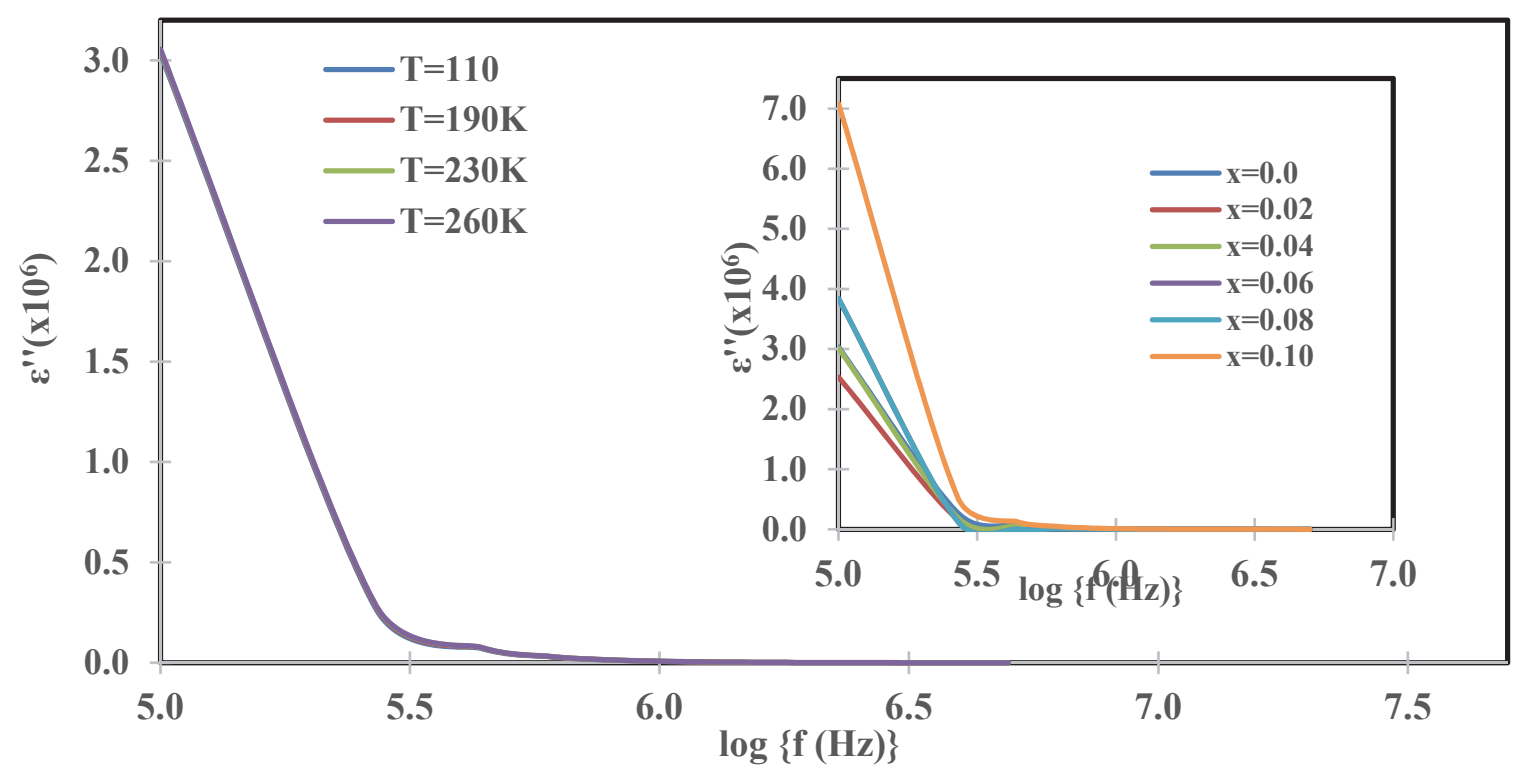

Figure 6. Frequency dependence of $\varepsilon$ " at different temperatures for $\left(\mathrm{Cu}_{0.5} \mathrm{Tl}_{0.5}\right) \mathrm{Ba}_{2} \mathrm{Ca}_{3} \mathrm{Cu}_{4} \mathrm{O}_{12-\delta}$. The inset represents the Frequency dependence of' $\varepsilon^{\prime \prime}$ at $\mathrm{T}=110 \mathrm{~K}$ for $\left((\mathrm{CH})_{\mathrm{n}}\right)_{\mathrm{x}} /\left(\mathrm{Cu}_{0.5} \mathrm{Tl}_{0.5}\right) \mathrm{Ba}_{2} \mathrm{Ca}_{3} \mathrm{Cu}_{4} \mathrm{O}_{12-\delta}$ with 0.00

$$
\leq \mathrm{x} \leq 0.10 \text { wt. } \%
$$

Dielectric loss or $\tan \delta$ is usually referred to as dissipation factor and it is significant to understand the mechanisms of dielectric relaxation and ac conduction. The dependence of dielectric loss on the frequency at different temperatures for $\left(\mathrm{Cu}_{0.5} \mathrm{Tl}_{0.5}\right) \mathrm{Ba}_{2} \mathrm{Ca}_{3} \mathrm{Cu}_{4} \mathrm{O}_{12-\delta}$ is shown in figure 7. It shows that at low frequency the value of $\tan \delta$ slightly increased with increasing of temperature. The inset of figure 7 shows the frequency dependence of' $\tan \delta$ at $\mathrm{T}=110 \mathrm{~K}$ for $\left((\mathrm{CH})_{\mathrm{n}}\right)_{\mathrm{x}} /\left(\mathrm{Cu}_{0.5} \mathrm{Tl}_{0.5}\right) \mathrm{Ba}_{2} \mathrm{Ca}_{3} \mathrm{Cu}_{4} \mathrm{O}_{12-\delta}$ with $0.00 \leq \mathrm{x} \leq 0.10 \mathrm{wt}$. \%. At low frequency tan $\delta$ decreases for addition of graphene and attains its lowest value for $\mathrm{x}=0.04 \mathrm{wt} \%$ and then it increases for $\mathrm{x}>0.04 \mathrm{wt} \%$. 


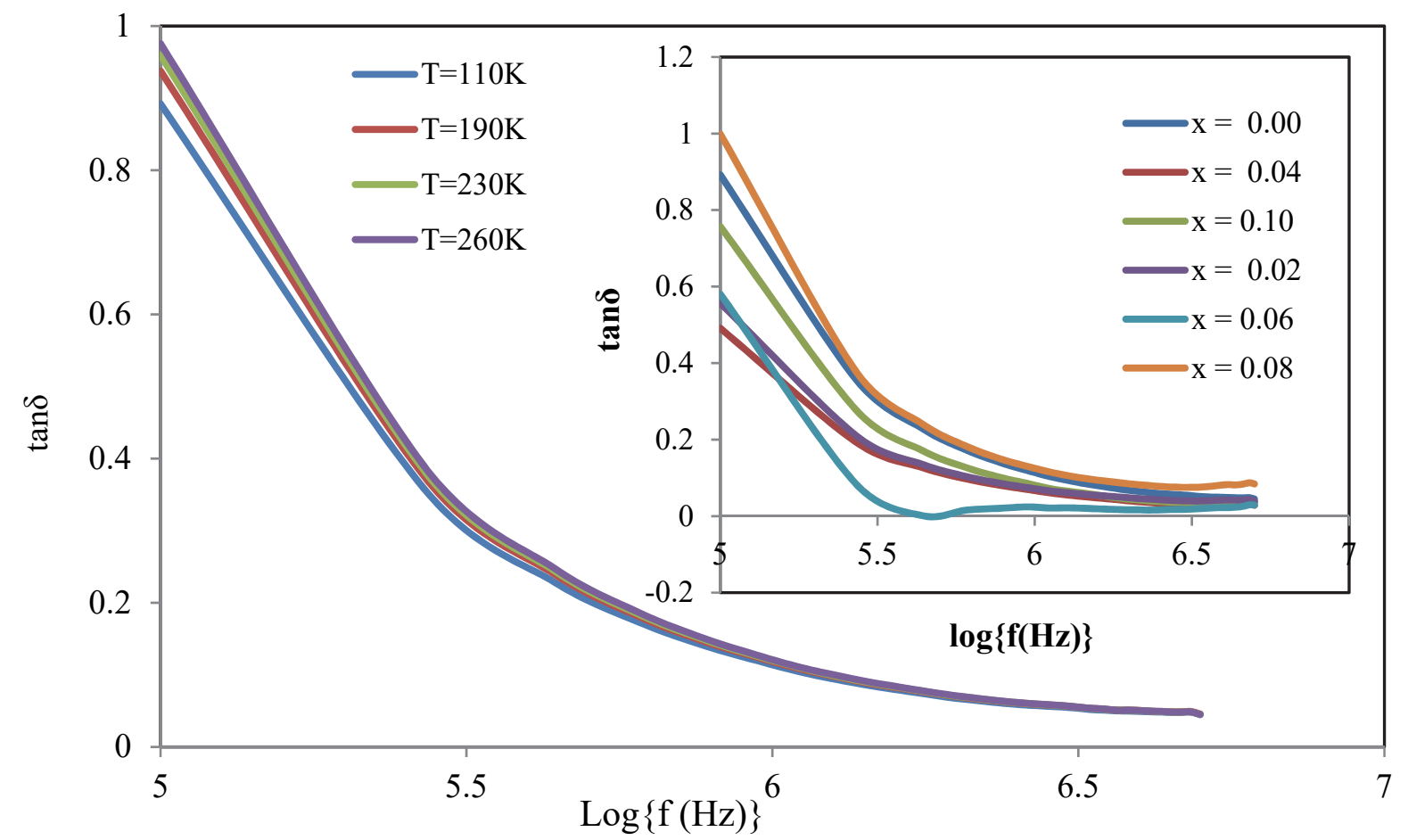

Figure 7. Frequency dependence of $\tan \delta$ at different temperatures $\left(\mathrm{Cu}_{0.5} \mathrm{Tl}_{0.5}\right) \mathrm{Ba}_{2} \mathrm{Ca}_{3} \mathrm{Cu}_{4} \mathrm{O}_{12-\delta}$. The inset represents the Frequency dependence of $\tan \delta$ at $\mathrm{T}=110 \mathrm{~K}$ for $\left((\mathrm{CH})_{\mathrm{n}}\right)_{\mathrm{x}} /\left(\mathrm{Cu}_{0.5} \mathrm{Tl}_{0.5}\right) \mathrm{Ba}_{2} \mathrm{Ca}_{3} \mathrm{Cu}_{4} \mathrm{O}_{12-\delta}$ with $0.00 \leq \mathrm{x} \leq$ 0.10 wt. $\%$.

The variations of $\sigma_{\mathrm{ac}}$ with frequency for pure sample at different temperatures (Fig.8) and its variation with frequency for different $\mathrm{x}$ at $\mathrm{T}=110 \mathrm{~K}$ (inset of figure 8) follow a similar behavior to that of $\varepsilon^{\prime}$ and $\varepsilon^{\prime \prime}$. The values of $\sigma_{\mathrm{ac}}$ is not temperature dependent, however it shows an increase with $\mathrm{x}$. The increase trend in $\sigma_{\mathrm{ac}}$ at fixed temperature of $110 \mathrm{~K}$ with the addition of graphene is also observed.

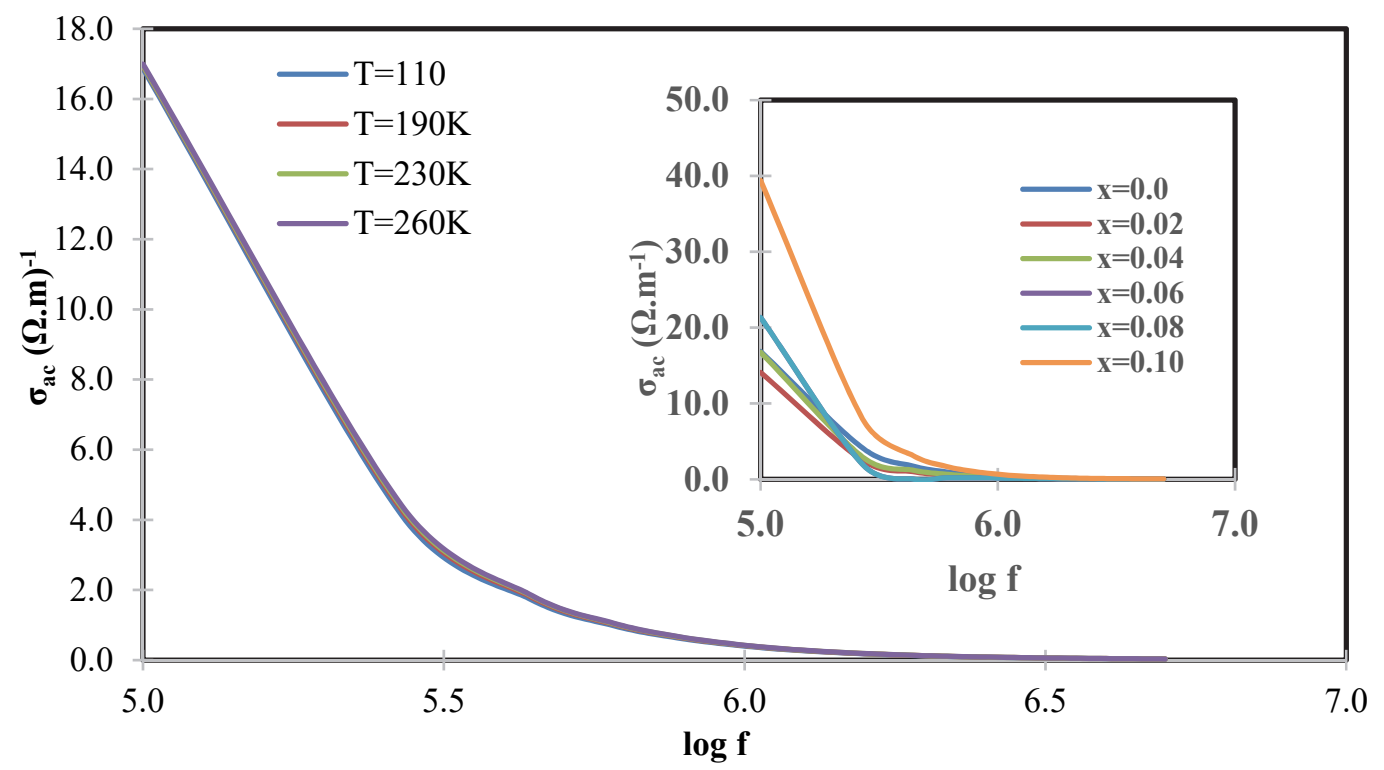

Figure 8. Frequency dependence of $\sigma a c$ at different temperatures $\left(\mathrm{Cu}_{0.5} \mathrm{Tl}_{0.5}\right) \mathrm{Ba}_{2} \mathrm{Ca}_{3} \mathrm{Cu}_{4} \mathrm{O}_{12-\delta}$. The inset represents the Frequency dependence of' $\sigma_{\mathrm{ac}}$ at $\mathrm{T}=110 \mathrm{~K}$ for $((\mathrm{CH}) \mathrm{n})_{\mathrm{x}} /\left(\mathrm{Cu}_{0.5} \mathrm{Tl}_{0.5}\right) \mathrm{Ba}_{2} \mathrm{Ca}_{3} \mathrm{Cu}_{4} \mathrm{O}_{12-\delta}$ with $0.00 \leq \mathrm{x} \leq$ 0.10 wt. $\%$ 


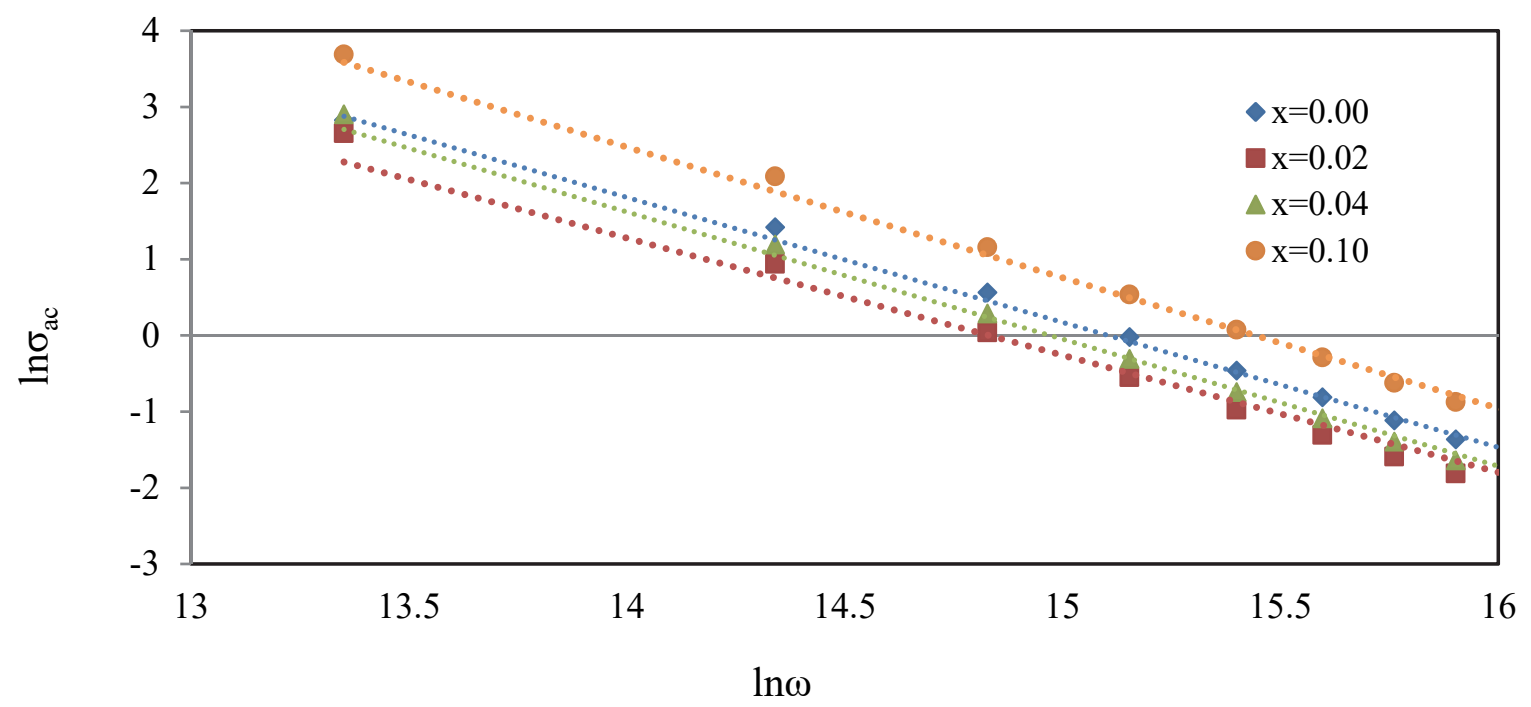

Figures 9. the plot of $\ell n \sigma_{a c}$ versus $\ell n \omega$ for for $\left((\mathrm{CH})_{n}\right)_{x} /\left(\mathrm{Cu}_{0.5} \mathrm{Tl}_{0.5}\right) \mathrm{Ba}_{2} \mathrm{Ca}_{3} \mathrm{Cu}_{4} \mathrm{O}_{12-}$ at $\mathrm{t}=110 \mathrm{~K}$ for different $\mathrm{x}$

\section{Discussion}

The shift in the most intense peak in the XRD graphs is probably due to the increase of $\mathrm{BaCuO}_{2}$ which depend on the vapor pressure inside the preparation tube [17]. Small amounts of $\mathrm{BaCuO}_{2}$ and $\left(\mathrm{Cu}_{0.5}, \mathrm{Tl}_{0.5}\right)-1223$ phases appears in the XRD pattern. The lattice parameters have shown unsystematic variation with the addition of graphene. Thus, the graphene addition may occupy the viods between the superconductor grains without entering inside (CuTl)1234 crystal structure. The suppression in the volume fraction means that high concentrations of graphene addition retards the formation of $(\mathrm{Cu}, \mathrm{Tl})-1234$. This might be attributed to the change in viscosity and homogeneity of the of the transient liquid formed at the reaction temperature.

For low concentration percentages $(0.02 \leq \mathrm{x} \leq 0.04)$, addition of graphene improves the formation of rectangular grains as shown in Fig. 2(b) where the optimal is at $x=0.04 \mathrm{wt}$. \%. This was confirmed by the improvement of volume fraction as discussed before in XRD results. The size of the grains is not highly affected but the increase in the connectivity and reduction of pores is recognizable. This is due to the presence of graphene at grain boundaries and its occupation of the void regions, which causes an improvement of the inter-grain connectivity of superconductor matrix. It should be noted that graphene was prepared separately and then it was added to (CuTl)1234 superconductor matrix, thus the place where these particles can reside is only the superconductor grain surfaces and/or between grains. For high concentration of graphene addition, the rectangular shapes increase in size up to $\mathrm{x}=0.08 \mathrm{wt} . \%$ as shown in figure $2 \mathrm{c}$ and then it disappears gradually up to $\mathrm{x}=0.10 \mathrm{wt} . \%$. This can be attributed to the decrease in the volume fraction of the main phase and the formation of secondary phases such as $(\mathrm{Cu}, \mathrm{Tl})-1223$.

The values of $T_{\mathrm{c}}$ plotted in the inset of figure 3 , increase from $108 \mathrm{~K}$ for the pure sample to $116 \mathrm{~K}$ for the sample with $\mathrm{x}=0.04 \mathrm{wt} . \%$ with an enhancement rate of $7.4 \%$. For $\mathrm{x}>0.04, T_{c}$ decreases to attain its minimum value of $95 \mathrm{~K}$ for $\mathrm{x}=0.1 \mathrm{wt}$. $\%$. with a retardation rate of $12 \%$. The behavior of $T_{c}$ is compatible with the behavior of the volume fraction of $(\mathrm{Cu}-\mathrm{Tl})-1234$ superconducting phase obtained from XRD measurements. The increase in $T_{c}$ is a consequence of the improvement of weak links through grain boundaries due to the addition of graphene which fills the pores and consequently increase the electrical contacts between the grains. The suppression of $T_{c}$ may be attributed to the decrease in the volume fraction of the main phase [19], $(\mathrm{Cu}, \mathrm{Tl})-1234$ phase or the trapping of mobile carriers. Another explanation might be that for high additions, graphene gets agglomerated at grain boundaries increasing their resistance, as being an allotrope of carbon which is known for deterioration of superconductivity. Barik et al. [20], reported that high amounts of nano particles addition enhances the mechanism of cooper pair breaking, this might be a reason for the deterioration of the superconducting properties with high additions of graphene.

Observing the FTIR spectra plotted in figure 4, we observe a small variation in the oxygen modes $\mathrm{O}_{\delta}$ in the reservoir layer ranges between 668 to $680 \mathrm{~cm}^{-1}$. The apical oxygen modes of type Tl-OA-Cu(2), apical oxygen mode of type $\mathrm{Cu}(1)-\mathrm{OA}-\mathrm{Cu}(2)$ and planner oxygen mode $\mathrm{Cu}(2)-\mathrm{OP}-\mathrm{Cu}(2)$ show a disturbance variation in the 
position of oxygen modes with few unchangeable peaks. Its is believed that the stress and strains induced by the addition of graphene affect the bond length and hence causes a variation in the position of these modes. However, these results indicate the non-homogenous distribution of graphene inside the superconducting matrix.

The decrease in the values of $\varepsilon^{\prime}$ with frequency as shown in figure 5 is attributed to the decrease in the dipolar polarization contribution due to large inertia of oscillating dipoles; hence the time constant of the applied field is shorter than the dipolar polarization characteristic time at high frequencies of applied field [11]. In fact, at low frequency the carriers can follow the frequency of the external applied ac field and at higher frequency the period becomes very short and hence the carriers cannot follow the field and the response of the sample becomes insignificant. For high frequencies beyond $1 \mathrm{MHz}$, the dielectric constant $\varepsilon^{\prime}$ becomes temperature independent confirming that $\varepsilon^{\prime}$ originates from electronic and lattice polarizations on account of their short relaxation time relative to the time constant of the applied field [10]. On the other hand, $\varepsilon^{\prime}$ shows a decrease with the increase of temperature resulting from the decrease in polarizability due to thermal agitation. This result confirms that the superconducting phase is comprised of strongly coupled carriers [21]. This high value of $\varepsilon^{\prime}$ for $x=0.1$ at $T=110 \mathrm{~K}$, as shown in the inset of figure 5 is attributed to the effect of high concentration addition of graphene in the enhancement of the formation of impurities resulting from secondary phases, and scattering at grain boundaries, consistent with the smallest value of volume fraction and $T_{c}$ obtained from XRD and ac susceptibility measurements respectively for the sample of $\mathrm{x}=0.10 \mathrm{wt} . \%$.

The Maxwell- Wagner model [22] in addition to Koop's phenomenological theory [23] are used to interpret the dielectric response of our samples. According to these models, a dielectric medium is composed of two parts: strongly conducting grains with high values of permittivity surrounded by weak grain boundaries with low values of permittivity. At lower frequencies the grain boundaries show a higher response than electrical conduction grains. The sample with $\mathrm{x}=0.10 \mathrm{wt} . \%$ recorded the highest value of $\varepsilon$ " probably due to the accumulation of high concentration of graphene at the grain boundaries.

The behavior of $\tan \delta$ shown in figure 7 and its inset is compatible with the results of SEM and volume fraction calculations. This behavior correlates with the enhancement of the superconducting properties with the addition of graphene till a certain concentration $(\mathrm{x}=0.04 \mathrm{wt} \%)$ above which further addition of graphene causes a deterioration of the superconducting properties.

The rise of the values of $\sigma_{\mathrm{ac}}$ with the addition of graphene at $\mathrm{T}=110 \mathrm{~K}$ as shown in figure 8 is an indication of the enhancement of the inter-granular links. This is due to the fact that graphene nanoparticles occupy the grain boundaries and heal up the cracks by filling the pores and voids. The drop of ac conductivity with the increase in frequency suggests that it arises due to the free carriers [24]. Several superconductors including $\mathrm{Bi}_{2} \mathrm{Sr}_{2} \mathrm{Ca}_{2} \mathrm{Cu}_{3} \mathrm{O}_{10}$, $\mathrm{Bi}_{2} \mathrm{Sr}_{2} \mathrm{CaCu}_{2} \mathrm{O}_{8}$ and $\mathrm{YBa}_{2} \mathrm{Cu}_{3} \mathrm{O}_{6}$ were reported in literature [25] and [26] to behave similarly in the infra-red frequency range.

The frequency dependence of $\sigma_{\mathrm{ac}}$ is expressed by the relation [27]

$$
\sigma_{a c}=Q \cdot \omega^{-s}
$$

where $\mathrm{Q}$ is the pre-exponential factor and $\mathrm{s}$ is the frequency exponent. If $\mathrm{s}<1$ it indicates the hopping motion is translational one, while if $s>1$ then the motion is a localized one. The values of $s$ in equation (4) were extracted from the slopes of the linear fits of plots of $\ell \mathrm{n}$ бac versus $\ell \mathrm{n} \omega$ at $\mathrm{T}=110 \mathrm{~K}$ that are represented in figure 9. All values of $s$ are greater than $1(\mathrm{~s}>1)$ which indicates that the hopping motion is localized. According to quantum mechanical tunneling model [28], the frequency exponent s depends on frequency and does not depend on temperature. The motion of carriers that give rise to ac conductivity does not cause a distortion in the lattice.

\section{Conclusions}

In this work, $\left((\mathrm{CH})_{\mathrm{n}}\right)_{\mathrm{x}} /\left(\mathrm{Cu}_{0.5} \mathrm{Tl}_{0.5}\right) \mathrm{Ba}_{2} \mathrm{Ca}_{3} \mathrm{Cu}_{4} \mathrm{O}_{12-\delta}$ superconducting phase was successfully prepared by conventional solid-state reaction technique, with $0.0 \mathrm{wt} . \% \leq \mathrm{x} \leq 0.1 \mathrm{wt}$. The lattice parameters had no significant variation with the addition of graphene while the volume fraction of the superconducting phase as well as the superconducting transition temperature $T_{\mathfrak{c}}$ were enhanced with $\mathrm{x}$ up to $0.04 \mathrm{wt} . \%$ and then deteriorated with further increase in $\mathrm{x}$. FTIR results indicated that the shift in wave number for each peak is a result of the sticking of the added graphene on the grain boundaries. The dielectric parameters including tan $\delta, \varepsilon^{\prime}, \varepsilon^{\prime \prime}$ and $\sigma_{\text {ac }}$ have shown a decrease due to the accumulation of high concentration of graphene on grain boundaries. The behavior of $\tan \delta$ was correlated to the effect of addition of graphene in enhancement of the superconducting parameters at low additions and the deterioration of the superconducting phase at higher addition of graphene. $\sigma_{\mathrm{ac}}$ was found to be temperature independent, but decreases with frequency. The frequency exponent factor (s) was found to be greater than one, indicating a localized hoping motion of carriers. As a conclusion, the dielectric parameters of 
$((\mathrm{CH}) \mathrm{n}) \mathrm{x} /(\mathrm{Cu} 0.5 \mathrm{~T} 10.5) \mathrm{Ba} 2 \mathrm{Ca} 3 \mathrm{Cu} 4 \mathrm{O} 12-\delta$ superconducting phase can be tuned by frequency, operating temperatures, and the amount of added graphene.

\section{Acknowledgements}

Samples preparation was conducted at the materials science lab-Beirut Arab University. The authors thank the superconductivity and metallic-glass lab at Alexandria University and the American University of Beirut.

\section{References}

Abou-Aly, A. I., Gawad, M. A., Awad, R., \& G-Eldeen, I. (2011). Improving the physical properties of (Bi, Pb)2223 phase by SnO 2 nano-particles addition. J. SUPERCOND. NOVEL MAGN, 24(7), 2077. https://doi.org/10.1007/s10948-011-1171-z

Aly, A. A., Mohammed, N. H., Awad, R., Motaweh, H. A., \& Bakeer, D. E. S. (2012). Determination of superconducting parameters of $\mathrm{GdBa}_{2} \mathrm{Cu}_{3} \mathrm{O}_{7-} \delta$ added with nanosized ferrite $\mathrm{CoFe}_{2} \mathrm{O}_{4}$ from excess conductivity analysis. J. SUPERCOND. NOVEL MAGN, 25(7), 2281-2290. https://doi.org/10.1007/s10948012-1621-2

Awad, R. (2008). Study of the Influence of MgO Nano-Oxide Addition on the Electrical and Mechanical Properties of ( $\mathrm{Cu} 0.25 \mathrm{Tl}$ 0.75)-1234 Superconducting Phase. J SUPERCOND. NOVEL MAGN, 21(8), 461-466. https://doi.org/10.1007/s10948-008-0385-1

Awad, R. (2009). Enhancement the formation of (Cu, Tl)-1223 superconducting phase by Cd-substitution. J. Alloys Compd, 474(1-2), 517-521. https://doi.org/10.1016/j.jallcom.2008.06.153

Barik, H. K., Ghorai, S. K., Bhattacharya, S., Kilian, D., \& Chaudhuri, B. K. (2000). Effect of Cr doping on the electrical conductivity and Seebeck coefficient in the superconductors obtained from the $\mathrm{Bi}-\mathrm{Pb}-\mathrm{Sr}-\mathrm{Ca}-\mathrm{Cu}-$ Cr-O-type glassy precursors by annealing. J. Mater. Res., 15, 1076. https://doi.org/10.1557/JMR.2000.0155

Cavdar, H. S., Koralay, N., Tugluoglu, \& Gunen, A. (2005). Frequency-dependent dielectric characteristics of T1$\mathrm{Ba}-\mathrm{Ca}-\mathrm{Cu}-\mathrm{O}$ bulk superconductor. Supercond Sci. Technol., 18, 1204. https://doi.org/10.1088/09532048/18/9/010

El Ata, A. A., Attia, S. M., \& Meaz, T. M. (2004). AC conductivity and dielectric behavior of $\mathrm{CoAl}_{\mathrm{x}} \mathrm{Fe}_{2-} \mathrm{O}_{4}$ Solid State Sci, 6(1), 61-69. https://doi.org/10.1016/j.solidstatesciences.2003.10.006

El Azrak, A., Nahoum, R., Bontemps, N., GuillouxViry, M., Thivet, C., Perrin, A., Labdi, S., Li, Z. Z., \& Raffy, H. (1994). Infrared properties of $\mathrm{YBa}_{2} \mathrm{Cu}_{3} \mathrm{O}_{7}$ and $\mathrm{Bi}_{2} \mathrm{Sr}_{2} \mathrm{Ca}_{\mathrm{n}-1} \mathrm{Cu}_{\mathrm{n}} \mathrm{O}_{2}{ }_{\mathrm{n}+4}$ thin films Phys. Rev. B., 49, 9846. https://doi.org/10.1103/PhysRevB.49.9846

Elliott, S. R. (1987). Ac conduction in amorphous chalcogenide and pnictide semiconductors.Advances in Physics, 36(2), 135-217. https://doi.org/10.1080/00018738700101971

Elokr, M. M., Awad, R., El-Ghany, A. A., Shama, A. A., \& El-Wanis, A. A. (2011). Effect of nano-sized ZnO on

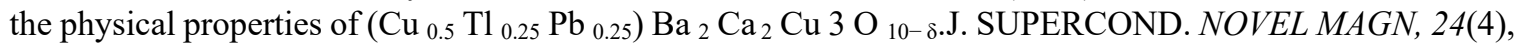
1345-1352. https://doi.org/10.1007/s10948-010-0831-8

Elsharkawy, S. G., \& Awad, R. (2009). Thermal expansion measurements of (Cu0. 25T10. 75)-1234 added by MgO-nano particles. Journal of Alloys and Compounds, 478, 642. https://doi.org/10.1016/j.jallcom.2008.11.120

Ihara, H., Tokiwa, K., Tanaka, K., Tsukamoto, T., Watanabe, T., Yamamoto, H., \& Umeda, M. (1997). "Cu1$\mathrm{xTlxBa} 2 \mathrm{Ca} 3 \mathrm{Cu} 4 \mathrm{O} 12-\mathrm{y}\left(\mathrm{Cu}_{1-\mathrm{x}} \mathrm{Tl} \mathrm{x}_{\mathrm{x}-1234}\right)$ superconductor with $\mathrm{Tc}=126 \mathrm{~K}$. Physica C: Superconductivity, 282, 957-958. https://doi.org/10.1016/S0921-4534(97)00592-3

Kamalasanan, M. N., Deepak Kumar, N., \& Chandra, S. (1993). Dielectric and ferroelectric properties of $\mathrm{BaTiO}_{3}$ thin films grown by the sol-gel process. J. Appl. Phys., 74, 5679. https://doi.org/10.1063/1.354183

Karaca, I., Celebi, S., Varilci, A., \& Malik, A. I. (2002). Effect of Ag2O addition on the intergranular properties of the superconducting $\mathrm{Bi}-(\mathrm{Pb})-\mathrm{Sr}-\mathrm{Ca}-\mathrm{Cu}-\mathrm{O}$ system. Superconductor Science and Technology, 16(1), 100.

Kong, W., Kechik, M. M. A., \& Abd-Shukor, R. (2018). Effect of graphene addition on the transport critical current density of bulk (T10. 85Cr0. 15) Sr2CaCu2O7- $\delta$ superconductor. Materials Today: Proceedings, 5(1), 31763184. https://doi.org/10.1016/j.matpr.2018.01.125

Koops, C. G. (1951). On the dispersion of resistivity and dielectric constant of some semiconductors at audiofrequencies. Phys. Rev., 83, 12. https://doi.org/10.1103/PhysRev.83.121

Mohammed, N. H. (2012). Effect of MgO nano-oxide additions on the superconductivity and dielectric properties 
of $\mathrm{Cu}_{0.25} \mathrm{Tl}_{0.75} \mathrm{Ba}_{2} \mathrm{Ca}_{3} \mathrm{Cu}_{4} \mathrm{O}_{12-\delta}$ superconducting phase. J. SUPERCOND. NOVEL MAGN, 25(1), 45-53. https://doi.org/10.1007/s10948-011-1207-4

Mumtaz, M., \& Khan, N. A. (2009). Reduced anti-ferromagnetism promoted by $\mathrm{Zn} 3 \mathrm{~d} 10$ substitution at $\mathrm{CuO} 2$ planar sites of Cu0. 5T10. 5Ba2Ca3Cu4O12- $\delta$ superconductors. Physica C: Superconductivity, 469(4), 182187. https://doi.org/10.1016/j.physb.2009.07.133

Mumtaz, M., Ali, L., Khan, M. N., \& Sajid. (2016). Tuning of Dielectric Parameters of $\left(\mathrm{NiFe}_{2} \mathrm{O}_{4}\right)$ x/CuTl 1223 Nano-superconductor Composites by Temperature and Frequency. M. U. Journal of J. SUPERCOND. NOVEL MAGN, 29(5), 1181-1186. https://doi.org/10.1007/s10948-016-3393-6

Puchkov, A. V., Basov, D. N., \& Timusk, T. (1996). The pseudogap state in high-superconductors: an infrared study. J. Phys., Condens. Matter, 8, 10049. https://doi.org/10.1088/0953-8984/8/48/023

Srour, A., Awad, R., Malaeb, W., \& Barakat, M. M. (2017). $\mathrm{BaSnO}_{3}\left(\mathrm{Cu}_{0.5} \mathrm{Tl}_{0.5} \mathrm{Ba}_{2} \mathrm{Ca}_{2} \mathrm{Cu}_{3} \mathrm{O}_{10-\delta}\right)$ J. Low Temp. Phys., 189(3-4), 217-229. https://doi.org/10.1088/1402-4896/aa86ce

Sudesh, K., N., Das, S., Bernhard, C., \& Varma, G. D (2013). Effect of graphene oxide doping on superconducting properties of bulk $\mathrm{MgB}_{2}$. Supercond. Sci. Technol, 26(9), 095008. https://doi.org/10.1088/09532048/26/9/095008

Vieira, V. N., Pureur, P., \& Schaf. (2002). Effects of $\mathrm{Zn}$ and $\mathrm{Mg}$ in $\mathrm{Cu}$ sites of $\mathrm{YBa} / \mathrm{sub} 2 / \mathrm{Cu} / \mathrm{sub} 3 / \mathrm{O} / \mathrm{sub} 7-$ [delta]/single crystals on the resistive transition, fluctuation conductivity, and magnetic irreversibilities.J. Phys. Rev. B: Condens. Matter, 66(22), 224506. https://doi.org/10.1103/PhysRevB.66.224506

Wagner, K. W. (1913). The theory of incomplete dielectricity. Ann. Phys., 40, 817.

Wei, K., Ing, K., Hamdan, M. S., Radiman, S., \& Abd-Shukor, R. (2018). 1-5. AC Susceptibility and

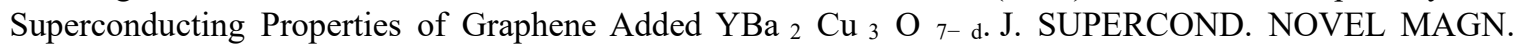
https://doi.org/10.1007/s10948-017-4536-0

Xu, X., Jiao, Z., Fu, M., Feng, L., Xu, K., Zuo, R., \& Chen, X. (2005) Dielectric studies in a layered Ba based Bi-

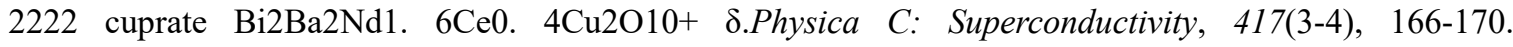
https://doi.org/10.1016/j.physc.2004.11.001

Younis, A., Khan, N. A., \& Bajwa, N. U. (2010) Dielectric properties of Cu0. 5T10. 5 $\mathrm{Ba}_{2} \mathrm{Ca}_{3} \mathrm{Cu}_{4-\mathrm{y}} \mathrm{ZnyO}_{12-\delta}(\mathrm{y}=0$, 3) superconductors. J Korean Phys Soc, 57, 1437-1443. http://dx.doi.org/10.3938/jkps.57.1437

Zangenberg, N., Nielsen, G., Hauge, N., Nielsen, B. R., Baurichter, A., Pedersen, C. G., \& Moller, S. P. (2012). Conduction cooled high temperature superconducting dipole magnet for accelerator applications. IEEE Transactions on Applied Superconductivity, 22(3), 4004004-4004004. https://doi.org/10.1109/TASC.2011.2178995

\section{Copyrights}

Copyright for this article is retained by the author(s), with first publication rights granted to the journal.

This is an open-access article distributed under the terms and conditions of the Creative Commons Attribution license (http://creativecommons.org/licenses/by/4.0/). 